\title{
Changes in Growth Characteristics of Seven Foliage Plants Grown in an Indoor Bio-Wall System Depending on Irrigation Cycle
}

\author{
Cheolgu Han ${ }^{1}$ and le-Sung Shim ${ }^{2 *}$ \\ ${ }^{1}$ Doctoral student, Department of Environmental Horticulture, University of Seoul. Seoul 02504, Korea \\ ${ }^{2}$ Professor, Department of Environmental Horticulture, University of Seoul, Seoul 02504, Korea
}

\section{ABSTRACT}

In order to increase the indoor air purification effect of plants, plants need to be placed on 5-10\% of indoor spaces. To increase the density and utilization of plants in indoor spaces, studies on bio-wall, a vertical green wall system, have been recently conducted. The purpose of this study was to investigate the growth characteristics of 7 indoor plants introduced to the system and their rooting zones at different irrigation cycles. This study was conducted to investigate a proper irrigation cycle for the continuous maintenance of bio-wall systems. The conditions of their growth environment were maintained as follows: light intensity, $20-50 \mu \mathrm{mol} \cdot \mathrm{m}^{-2} \cdot \mathrm{s}^{-1}$ PPFD; and temperature, $20-25^{\circ} \mathrm{C}$. For fertilization, Hyponex diluted with water at the ratio of 1:1,000 was supplied to plants. Irrigation was treated at intervals of 1, 3, 5, and 7 days for 1 hour at a time. As a result, there was no significant difference in the growth of plants between different irrigation cycles. Dieffenbachia 'Marianne' showed a significant decrease in the number of leaves at the irrigation cycle of 7 days. In addition, the chlorophyll content was relatively low at the irrigation cycle of 7 days. In terms of the color of leaves, a decrease in $L$ value and $b$ value and an increase in a value were observed, resulting in changes in brightness and color. Ardisia pusilla 'Variegata' showed a slightly higher photosynthetic activity and stomatal conductance when it was watered every day and once per 5 days, while Epipremnum aureum showed a relatively higher photosynthetic activity and stomatal conductance at the irrigation cycle of 3 days. In the case of root activity, it was found that the longer irrigation cycle, the higher root activity compared to daily irrigation. The development of roots of Peperomia clusiifolia was promoted by watering at long intervals. However, in the case of Aglaonema 'Siam-Aurora', the total number of roots decreased at the interval of 7 days. In conclusion, a proper irrigation cycle for the sustainable maintenance of vertical bio-wall systems seems to be 3 days.

Keywords: green-wall, indoor plants, photosynthesis, root activity, root development

\section{Introduction}

The amount of time that people in modern society spend on outdoor activities has gradually decreased due to rapid industrialization and urbanization, while they have spent more time in indoor spaces, which resulted in an increasing interest in indoor environments. It has been reported that unhealthy indoor environments negatively affect the health of humans, and that there is a significant relation between indoor environments and the occurrence of diseases (Mitchell et al., 2007). Over the last few decades, people's interest in indoor environments has been mostly focused on indoor air quality and many studies have been conducted on pollution of and improvements in air quality (Sundell, 2004; Wu et al., 2007). Major causes of indoor air pollution include $\mathrm{CO}_{2}$ produced by respiration in humans, volatile organic compounds (VOCs) produced by construction materials and furniture, chemicals like formaldehyde and last-

This study was supported by the 2019 Research and Development Project for the Convergence-based New Industrialization of the Forestry Industry Forestry of the Korea Forestry Promotion Institute (No. 2017065C10-1919-AB02).

Received: January 9, 2020, Revised: January 17, 2020, Accepted: February 19, 2020

First author: Cheolgu Han, paewha@naver.com, (1) https://orcid.org/0000-0002-0224-926X

*Corresponding author: Ie-Sung Shim, isshim@uos.ac.kr, (1) https://orcid.org/0000-0002-4492-2133 
ly particulate matter (PM2.5, PM10) that has recently emerged as a serious issue.

In the past, physical and chemical filtering methods that use ventilation systems were mainly used to remove indoor air pollutants, but the utilization of living things was suggested as an alternative in order to improve indoor air quality due to issues such as large-scale energy consumption required to maintain air conditioning systems (Wolverton and Wolverton, 1993). A series of studies on improved indoor air quality by plants and soil microorganisms have continuously reported their effects over the past four decades (Darlington et al., 2001; Guieysse et al., 2008). In particular, as people's interest in air purification through the utilization of plants has significantly increased recently, studies on improved indoor environments through the utilization of plants have been also actively conducted (Han and Lee, 2002; Kim et al., 2008; Park et al., 1999; Wolverton et al., 1989).

Plants exchange gases through stomata in the process of photosynthesis and respiration, which is known to purify air by absorbing and adsorbing indoor pollutants (Irga et al., 2018; Torpy, Zavattaro, and Irga, 2017). However, in order to improve plants' effect of air purification, it is necessary to place plants on $5 \sim 10 \%$ of indoor spaces, and studies on bio-wall, a vertical green wall system, have been actively conducted recently in order to increase the density and utilization of plants in places (Pettit et al., 2018). Since vertical green wall systems called bio-wall or green-wall systems feature a high density of plants per unit area, compared to potted plants placed on the floor, and consequently a high frequency of contact with other indoor pollutants, they have a high air purification capacity and actively induce indoor air flow through fans, which increases their pollutant removal efficiency and increases people's interest in those systems (Torpy, Clements, et al., 2017).

In order to improve the effects of bio-wall systems on indoor air purification, it is important to maintain a proper cycle of water supply for plants and this not only controls the air purification mechanism of plants through photosynthesis, but also affects the growth of rooting zones (Pérez-Urrestarazu et al., 2014). This, in turn, has a significant impact on the development and growth of plants introduced to those systems in the long term. Against this backdrop, this study aimed to examine the growth characteristics of major indoor plants and the development of their rooting zones depending on the irrigation cycle of a bio-wall system and to identify a proper irrigation cycle for the sustainable maintenance of bio-wall systems.

\section{Research Methods}

\section{Plants and cultivation environments}

Changes in the growth characteristics of indoor foliage plants and the development of their roots depending on irrigation cycle were measured, focusing on Peperomia clusiifolia, Ardisia pusilla 'Variegata', Aglaonema 'SiamAurora', Aglaonem, Dieffenbachia 'Marianne', Epipremnum aureum, and Hedera helix. Twenty units of each species of which aerial part is $15-25 \mathrm{~cm}$ tall and that have 5-10 leaves were purchased from a flower market, were transplanted in solid-wick bottom watering pots using bed soil for horticultural purposes - Dream Soil (Cham Grow Inc., Korea) - and were kept in a green house for 1 week for acclimatation.

A vertical bio-wall system (size: $10 \mathrm{~m}^{2}$ ) used in this study supplied moisture to plants using a bottom watering method through capillarity and was installed on a wall within the Plant Environment Research Center of the University of Seoul. The placement height of plants on the bio-wall system was divided into high, medium and low zones, and 6-7 units of each testing plant were placed using a randomized block method. To maintain a constant indoor growth environment for plants, the intensity of light was maintained at $20-50 \mu \mathrm{mol} \cdot \mathrm{m}^{-2} \cdot \mathrm{s}^{-1}$ PPFD using LED fluorescent lamps with a light period of 16 hours and the temperature was maintained at $20-25{ }^{\circ} \mathrm{C}$. For their nutrition management, Hyponex (N:P:K=6:10:5, HYPONeX, Japan) was diluted with irrigation water at the ratio of $1: 1,000$ and was supplied to plants once a month. Irrigation was performed at intervals of $1,3,5$ and 7 days for 1 hour at a time.

\section{Plant growth survey}

Water was supplied at irrigation intervals of $1,3,5$ and 
7 days for 3 months, and the growth characteristics of each testing plant including plant height, the number of leaves, leaf length and width, the number of tillers, chlorophyll content and leaf color were measured. In addition, their photosynthetic activity and stomatal conductance and the activity and development of roots were surveyed and analyzed. For those that have 1 tiller, the total number of leaves was counted, and for those that have multiple tillers, a base tiller was selected and the number of leaves on the tiller was counted. The 3-5th mature leaves ranked from the bottom in terms of growing point were surveyed to measure the leaf length and width of plants .

The chlorophyll content of 5-6 mature leaves were measured using a chlorophyll meter (SPAD-502 plus, Konica, Japan) and their mean value was used. The color of the 3-5th mature leaves ranked from the bottom in terms of growing point were measured using a chroma meter (CR-400, Konica, Japan). The photosynthetic activity and stomatal conductance of 3-5 mature leaves were measured using a portable photosynthesis system (Li-6400, Li-Cor, USA) under the following conditions: $400 \mathrm{ppm}$ of the concentration of $\mathrm{CO}_{2}$ and $40 \mu \mathrm{mol} \cdot \mathrm{m}^{-2} \cdot \mathrm{s}^{-1}$ PPFD of the intensity of light. Their mean value was used.

\section{Root activity measurement}

The root activity of plants was measured following the process of collecting roots of testing plants, extracting formazan using the TTC method (triphenyl-tetrazolium chloride method) and measuring the concentration of formazan using a UV spectro-photometer (UV-2450, Shimadzu, Japan). Roots of testing plants were collected and cleaned with distilled water and their moisture was removed by gently wrapping them with filter paper. The roots were cut into $2 \mathrm{~cm}$-long pieces, and $1 \mathrm{~g}$ of the prepared samples was put into a filtering flask. TTC (2, 3, 5 tri-phenyl tetrazolium chloride) solution $1 \%, 0.1 \mathrm{M}$ sodium phosphate buffer solution $\left(0.1 \mathrm{M} \mathrm{Na}_{2} \mathrm{H}_{2} \mathrm{PO}_{4} 39 \mathrm{~mL}\right.$ was mixed with $0.2 \mathrm{M}$ $\mathrm{Na}_{2} \mathrm{HPO}_{4} 61 \mathrm{~mL}$ to maintain the solution at $\mathrm{pH} 7.0$ and $200 \mathrm{~mL}$ was quantified) and distilled water were mixed in the ratio of 1:4:5, and the roots were soaked in $20 \mathrm{~mL}$ of the mixed solution. Using an aspirator (A-3S, Eyela, Japan), the filtering flask was fully deaerated until no bub- ble was generated within the solution, and the flask was placed in a constant-temperature water bath at $30^{\circ} \mathrm{C}$ in a dark place for 2 hours for reaction.

After reaction, $4 \mathrm{~mL}$ of $2 \mathrm{~N}$ sulfuric acid $\left(\mathrm{H}_{2} \mathrm{SO}_{4}\right)$ was added to the filtering flask to stop reaction, and the roots were removed from the flask. After removing moisture on the roots with gauze, they were placed in mortar and were added with $10 \mathrm{~mL}$ of ethyl acetate and quartz sand, being triturated. The final volume of the triturated roots was quantified with ethyl acetate to become $20 \mathrm{~mL}$ and formazan was extracted. The supernatant of the extracted formazan was separated and its absorbance was measured at $470 \mathrm{~nm}$ using a UV spectrophotometer (UV-2450, Shimadzu, Japan). Standard solutions of 1, 2, 5, 10, 15 and $20 \mathrm{ppm}$ were made by melting TPF with ethyl acetate, and their absorbance was measured at $470 \mathrm{~nm}$ using a UV spectrophotometer to generate a standard curve.

Root activity $\left(\mathrm{mg} \cdot \mathrm{g}^{-1} \cdot \mathrm{h}^{-1}\right)=$ Generated formazan $(\mathrm{mg}) /$ [Root fresh weight $(\mathrm{g}) \times$ Reaction time $(\mathrm{h})]$

\section{Statistical analysis}

Analysis of variance (ANOVA) was conducted using SAS (Statistical Analysis System, Version 9 for Window, SAS Institute Inc., Cary, NC, USA) on changes in the growth of the aerial part of foliage plants introduced to the bio-wall system depending on the cycle of irrigation, and the level of significance was set at $p=.05$. Duncan's multiple range test was performed to compare the mean value of each item.

\section{Results and Discussion}

\section{Changes in the growth of aerial parts depending on irrigation cycle}

The leaf stalks of plants introduced to indoor vertical walls grow too long or outgrow the walls, and this phenomenon can be attributed to too low indoor light intensity or excessive moisture in the underground part of plants, which is known to reduce their ornamental values and growth (Ro et al., 2003). The growth characteristics of each 
plant that was watered once per $1,3,5$ and 7 days for 3 months. The plant length of Peperomia clusiifolia watered at the intervals of 3 and 5 days was slightly longer than other treatment groups, but the results were not statistically significant (Table 1). The number of leaves of Peperomia clusiifolia watered at the interval of 7 days tended to be high, but not statistically significant. There was also no significant difference in chlorophyll content and leaf color between treatment groups (Table 1). The plant length of Ardisia pusilla 'Variegata' did not show any significant difference between irrigation cycles, which was similar to the results of Jang et al. (2013). In terms of the number of leaves, the group watered at the interval of 5 days tended to be slightly low, but not statistically significant. No change in chlorophyll content and leaf color was observed.

The plant length of Aglaonema 'Siam-Aurora' tended to show a slight increase depending on the cycle of irrigation, and the number of leaves at the irrigation cycle of 7 days slightly decreased, but not statistically significant. It was found that the shorter the cycle of irrigation, the higher the content of chlorophyll, and that the longer the

Table 1. Growth characteristics of indoor plants grown in a bio-wall system for 3 months as influenced by irrigation interval cycle

\begin{tabular}{|c|c|c|c|c|c|c|c|}
\hline \multirow{2}{*}{ Plant species } & \multirow{2}{*}{$\begin{array}{l}\text { Irrigation } \\
\text { interval }\end{array}$} & \multirow{2}{*}{$\begin{array}{l}\text { Plant height } \\
\text { (cm) }\end{array}$} & \multirow{2}{*}{ No. of leaves } & \multirow{2}{*}{$\begin{array}{c}\text { Chlorophyll } \\
\text { contents (SPAD) }\end{array}$} & \multicolumn{3}{|c|}{ Leaf color (Hunter's values) } \\
\hline & & & & & $\mathrm{L}$ & $\mathrm{a}$ & $\mathrm{b}$ \\
\hline \multirow{4}{*}{$\begin{array}{l}\text { Peperomia } \\
\text { clusiifolia }\end{array}$} & 1 day & $21.5 \mathrm{a}^{\mathrm{z}}$ & $6.6 \pm 1.1 \mathrm{a}$ & $76.5 \mathrm{a}$ & $31.7 \mathrm{a}$ & $-10.0 \mathrm{a}$ & $11.0 \mathrm{a}$ \\
\hline & 3 days & $23.1 \mathrm{a}$ & $6.1 \pm 1.5 \mathrm{a}$ & $72.4 \mathrm{a}$ & $30.5 \mathrm{a}$ & $-9.1 \mathrm{a}$ & $9.0 \mathrm{a}$ \\
\hline & 5 days & $24.2 \mathrm{a}$ & $6.2 \pm 0.8 \mathrm{a}$ & $77.9 \mathrm{a}$ & $30.6 \mathrm{a}$ & $-9.2 \mathrm{a}$ & $9.2 \mathrm{a}$ \\
\hline & 7 days & $22.6 \mathrm{a}$ & $7.1 \pm 0.9 \mathrm{a}$ & $74.6 \mathrm{a}$ & $32.7 \mathrm{a}$ & $-10.2 \mathrm{a}$ & $10.8 \mathrm{a}$ \\
\hline \multirow{4}{*}{$\begin{array}{l}\text { Ardisia pusilla } \\
\text { 'Variegata' }\end{array}$} & 1 day & $25.5 \mathrm{a}$ & $11.0 \pm 1.8 \mathrm{a}$ & $44.3 \mathrm{a}$ & $37.6 \mathrm{a}$ & $-9.4 \mathrm{a}$ & $11.9 \mathrm{a}$ \\
\hline & 3 days & $25.3 \mathrm{a}$ & $10.7 \pm 1.6 \mathrm{a}$ & $45.3 \mathrm{a}$ & $38.0 \mathrm{a}$ & $-9.1 \mathrm{a}$ & $11.1 \mathrm{a}$ \\
\hline & 5 days & $25.7 \mathrm{a}$ & $9.4 \pm 2.0 \mathrm{a}$ & $44.7 \mathrm{a}$ & $37.4 \mathrm{a}$ & $-9.3 \mathrm{a}$ & $11.9 \mathrm{a}$ \\
\hline & 7 days & $25.5 \mathrm{a}$ & $11.0 \pm 1.6 \mathrm{a}$ & $45.3 \mathrm{a}$ & $38.8 \mathrm{a}$ & $-9.7 \mathrm{a}$ & $12.3 \mathrm{a}$ \\
\hline \multirow{4}{*}{$\begin{array}{l}\text { Aglaonema } \\
\text { 'SiamAurora' }\end{array}$} & 1 day & $26.8 \mathrm{a}$ & $13.1 \pm 2.3 \mathrm{a}$ & $41.1 \mathrm{a}$ & $29.7 \mathrm{a}$ & $8.0 \mathrm{a}$ & $10.1 \mathrm{a}$ \\
\hline & 3 days & $27.2 \mathrm{a}$ & $13.6 \pm 1.1 \mathrm{a}$ & $43.6 \mathrm{a}$ & $31.0 \mathrm{a}$ & $9.4 \mathrm{a}$ & $11.9 \mathrm{a}$ \\
\hline & 5 days & $27.1 \mathrm{a}$ & $14.0 \pm 1.0 \mathrm{a}$ & $36.7 \mathrm{a}$ & $30.1 \mathrm{a}$ & $7.9 \mathrm{a}$ & $10.7 \mathrm{a}$ \\
\hline & 7 days & $28.3 \mathrm{a}$ & $12.7 \pm 1.5 \mathrm{a}$ & $35.0 \mathrm{a}$ & $30.8 \mathrm{a}$ & $9.7 \mathrm{a}$ & $11.6 \mathrm{a}$ \\
\hline \multirow{4}{*}{$\begin{array}{l}\text { Aglaonema } \\
\text { commutatum }\end{array}$} & 1 day & $27.2 \mathrm{a}$ & $13.6 \pm 1.6 \mathrm{a}$ & $68.0 \mathrm{a}$ & $26.7 \mathrm{a}$ & $-7.1 \mathrm{a}$ & $7.4 \mathrm{a}$ \\
\hline & 3 days & $28.1 \mathrm{a}$ & $14.3 \pm 2.1 \mathrm{a}$ & $69.9 \mathrm{a}$ & $28.2 \mathrm{a}$ & $-6.7 \mathrm{a}$ & $7.2 \mathrm{a}$ \\
\hline & 5 days & $28.6 \mathrm{a}$ & $13.6 \pm 2.1 \mathrm{a}$ & $67.9 \mathrm{a}$ & $27.6 \mathrm{a}$ & $-6.6 a$ & $7.0 \mathrm{a}$ \\
\hline & 7 days & $29.0 \mathrm{a}$ & $13.4 \pm 1.5 \mathrm{a}$ & $66.7 \mathrm{a}$ & $27.2 \mathrm{a}$ & $-6.4 \mathrm{a}$ & $6.7 \mathrm{a}$ \\
\hline \multirow{4}{*}{$\begin{array}{c}\text { Dieffenbachia } \\
\text { amoena } \\
\text { 'Marianne' }\end{array}$} & 1 day & $32.0 \mathrm{a}$ & $8.1 \mathrm{a}$ & $50.2 \mathrm{a}$ & $33.8 \mathrm{a}$ & $-15.0 \mathrm{a}$ & $19.1 \mathrm{a}$ \\
\hline & 3 days & $31.8 \mathrm{a}$ & $8.0 \mathrm{a}$ & $48.5 \mathrm{a}$ & $33.2 \mathrm{a}$ & $-14.0 \mathrm{a}$ & $17.4 \mathrm{a}$ \\
\hline & 5 days & $31.2 \mathrm{a}$ & $7.4 \mathrm{ab}$ & $52.3 \mathrm{a}$ & $31.7 \mathrm{a}$ & $-12.0 \mathrm{a}$ & $13.6 \mathrm{a}$ \\
\hline & 7 days & $30.2 \mathrm{a}$ & $5.2 \mathrm{~b}$ & $44.0 \mathrm{a}$ & $32.7 \mathrm{a}$ & $-14.1 \mathrm{a}$ & $17.1 \mathrm{a}$ \\
\hline \multirow{4}{*}{$\begin{array}{l}\text { Epipremnum } \\
\text { aureum }\end{array}$} & 1 day & $45.3 \mathrm{a}$ & $9.4 \mathrm{a}$ & $46.3 \mathrm{a}$ & $34.7 \mathrm{a}$ & $-14.2 \mathrm{a}$ & $19.2 \mathrm{a}$ \\
\hline & 3 days & $46.7 \mathrm{a}$ & $10.0 \mathrm{a}$ & $43.9 \mathrm{a}$ & $33.3 \mathrm{a}$ & $-13.4 \mathrm{a}$ & $16.7 \mathrm{a}$ \\
\hline & 5 days & $43.1 \mathrm{a}$ & $9.3 \mathrm{a}$ & $44.9 \mathrm{a}$ & $35.8 \mathrm{a}$ & $-14.1 \mathrm{a}$ & $18.9 \mathrm{a}$ \\
\hline & 7 days & $43.4 \mathrm{a}$ & $8.5 \mathrm{a}$ & $45.7 \mathrm{a}$ & $33.5 \mathrm{a}$ & $-14.4 \mathrm{a}$ & $18.7 \mathrm{a}$ \\
\hline \multirow{4}{*}{ Hedera helix } & 1 day & $41.4 \mathrm{a}$ & $19 \mathrm{a}$ & $49.0 \mathrm{a}$ & $38.5 \mathrm{a}$ & $-15.2 \mathrm{a}$ & $21.3 \mathrm{a}$ \\
\hline & 3 days & $40.8 \mathrm{a}$ & $20 \mathrm{a}$ & $53.1 \mathrm{a}$ & $38.6 \mathrm{a}$ & $-15.1 \mathrm{a}$ & $20.3 \mathrm{a}$ \\
\hline & 5 days & $42.5 \mathrm{a}$ & $24 \mathrm{a}$ & $51.6 \mathrm{a}$ & $37.5 \mathrm{a}$ & $-15.2 \mathrm{a}$ & $20.8 \mathrm{a}$ \\
\hline & 7 days & $39.9 \mathrm{a}$ & $20 \mathrm{a}$ & $49.7 \mathrm{a}$ & $38.4 \mathrm{a}$ & $-15.0 \mathrm{a}$ & $20.3 \mathrm{a}$ \\
\hline
\end{tabular}

${ }^{\mathrm{Z}}$ Mean separation within column by Duncan's multiple range test at $p<.05$. 
cycle of irrigation, the the lower the content of chlorophyll (Table 1). Aglaonema did not show any significant difference in plant length and the number of leaves between irrigation cycles, and no change in the chlorophyll content and color of leaves was also observed.

Dieffenbachia 'Marianne' did not show any significant difference in plant length between irrigation cycles, but when the interval was long ( 7 days), the number of leaves was significantly reduced. This can be attributed to the increasing abscission of leaves caused by drying. In addition, the content of chlorophyll was relatively low at the irrigation cycle of 7 days, and in terms of the color of leaves, Dieffenbachia 'Marianne' showed a decrease in the L value, an increase in the a value and a decrease in the $b$ value, showing changes in the color of leaves such as a slight decrease in brightness, a decrease in the color of yellow and a slight increase in the color of red (Table 1).

Choi and Kim (2014) reported that it is difficult to maintain the patterns and colors of leaves of Epipremnum aureum under different conditions of indoor light intensity and humidity, but, in this study, the plant length of Epipremnum aureum at short irrigation cycles tended to be slightly long. The differences, however, were not significant and there was also no significant difference in the number of leaves. Its chlorophyll content and leaf color also did not show any significant difference (Table 1). The plant length and the number of leaves of Hedera helix at the irrigation cycle of 5 days slightly increased. The content of chlorophyll at the irrigation cycle of 3 days slightly increased, but not statistically significant. There was also no significant difference in the color of leaves (Table 1).

Changes in the photosynthetic activity and stomatal conductance of foliage plants depending on the cycle of irrigation were analyzed (Figs 1 and 2). There was no difference in the photosynthetic activity of Aglaonema between treatment groups, and the stomatal conductance tended to decrease as the cycle of irrigation increased (Fig. 2A). Dieffenbachia 'Marianne' showed a slight increase in photosynthetic activity when it was watered at the interval of 7 days, but not statistically significant, and there was also no difference in stomatal conductance (Fig. 2D). Aglaonema 'Siam-Aurora' showed a slight increase in photosynthetic activity at the irrigation cycles of 5 and 7 days (Fig. 1B), and its stomatal conductance was very low at the interval of 1 day, and high at the intervals of 3,5 and 7 days (Fig. 2B). In the case of Peperomia clusiifolia, the amount of photosynthesis was higher than the amount of respiration only at the irrigation cycle of 3 days (Fig. 1G), but other treatment groups showed a higher amount of respiration than photosynthesis. The stomatal conductance of Peperomia clusiifolia at the irrigation cycle of 3 days was also high (Fig. 2G). Hedera helix showed a slightly high photosynthetic activity and a high stomatal conductance at the irrigation cycles of 5 and 7 days (Figs. 1F and 2F). Ardisia pusilla 'Variegata' showed a slightly high photosynthetic activity and stomatal conductance when it was watered everyday and once per 5 days, while Epipremnum aureum showed a relatively high photosynthetic activity and stomatal conductance only when it was watered once per 3 days (Figs. 1 and 2).

The cyle of irrigation showed different effects on the growth of the aerial part of foliage plants in the indoor bio-wall system depending on the species of foliage plants, but the low photosynthetic activity of plants caused by a low light intensity in indoor environments seemed to lower the vegetative growth of plants. Improper fertilization and irrigation in a low vegetative state have a negative impact on the growth of plants. For this reason, it will be more necessary to conduct additional studies under different fertilization conditions for efficient and sustainable management for indoor bio-wall systems.

\section{Changes in the characteristics of underground parts depending on irrigation cycle}

The root activity of testing plants depending on the cycle of irrigation was examined. While Peperomia clusiifolia showed a high root activity when it was watered at the interval of 7 days (Fig. 3F), Aglaonema did not show any difference between treatment groups. Ardisia pusilla 'Variegata' showed a higher root activity at the irrigation cycles of 3 and 7 days than at the irrigation cycle of 1 day (Fig. 3C), and Dieffenbachia 'Marianne' showed a higher root activity at long irrigation cycles than at the cycle of 1 day (Fig. 3D). Aglaonema 'Siam-Aurora' also showed a higher root activity at slightly long irrigation cy- 


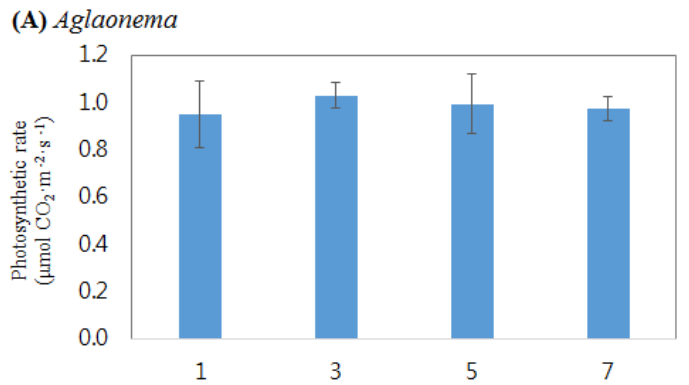

(C) Ardisia pusilla 'Variegata'

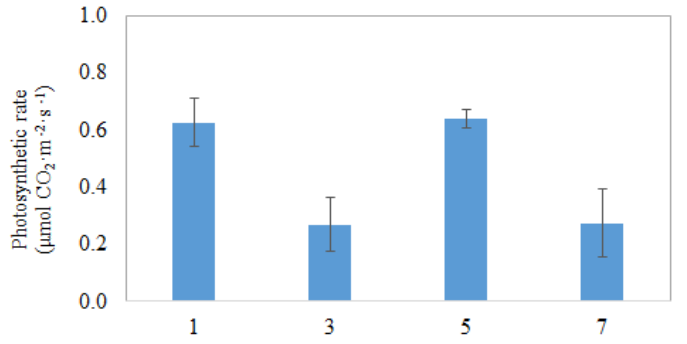

(E) Epipremnum aureum

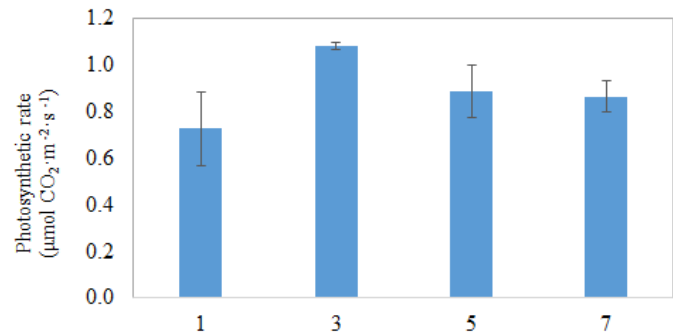

(G) Peperomia clusiifolia

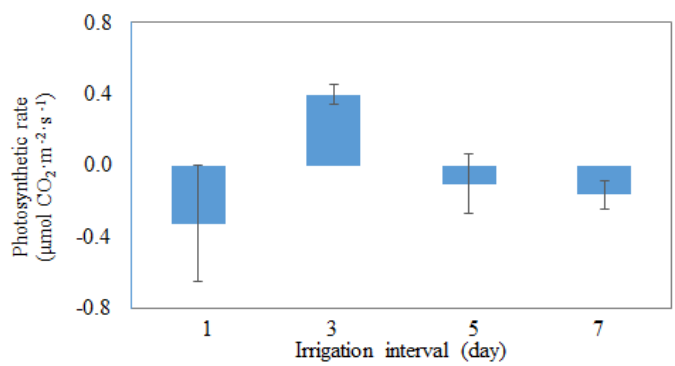

(B) Aglaonema 'Siam_Aurora'

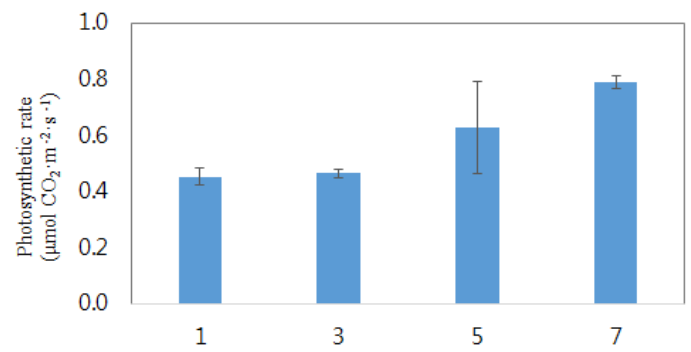

(D) Dieffenbachia 'Marianne'

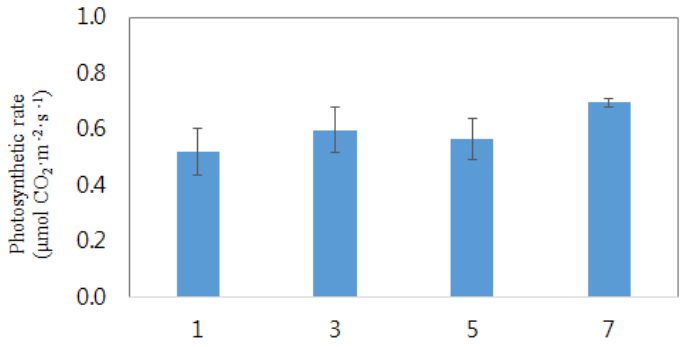

(F) Hedera helix

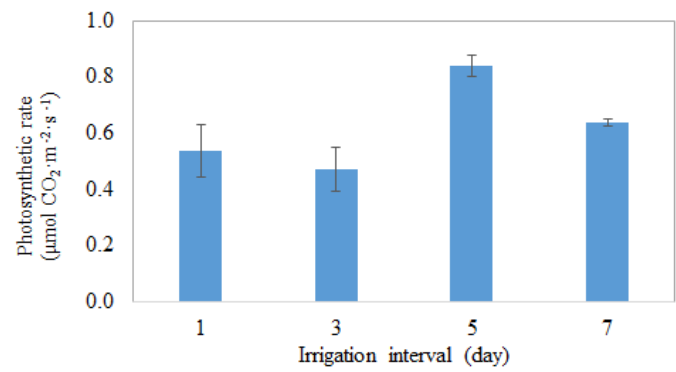

Fig. 1. Effect of irrigation interval cycle on photosynthesis of indoor plants grown for 3 months in a bio-wall system. Vertical bars indicate the standard deviation of three separate experiments.

cles than at the interval of 1 day, and Epipremnum aureum watered at the interval of 3 days was found to be good for the activity of roots (Fig. 3E).

The development of roots of Peperomia clusiifolia at different irrigation cycles was measured, and was found to be accelerated at long irrigation cycles. The length of roots at the longest cycle of irrigation (7 days) was also the longest, and the fresh weight of roots at the irrigation cycles of 3 and 7 days was higher than at the interval of
1 day. These results indicate that a proper irrigation cycle for Peperomia clusiifolia is 3 or 7 days, but considering that drying was also observed at the interval of 7 days, watering once per 3 days seems to be suitable for the plant (Figs. 4G and 5G).

The total number of roots of Ardisia pusilla 'Variegata' was not found to be significantly affected by the cycle of irrigation. Short roots were observed more in the treatment groups of short irrigation cycles, and the number of long 
(A) Aglaonema

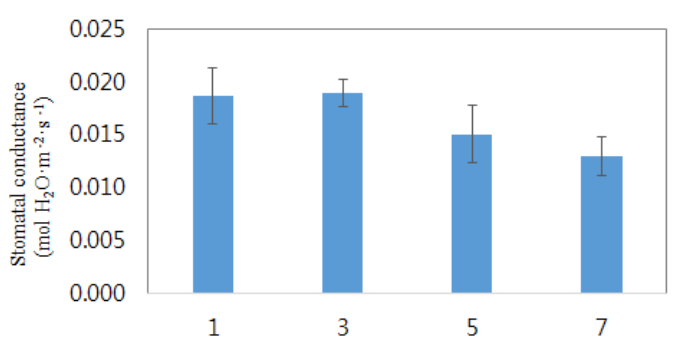

(C) Ardisia pusilla 'Variegata'

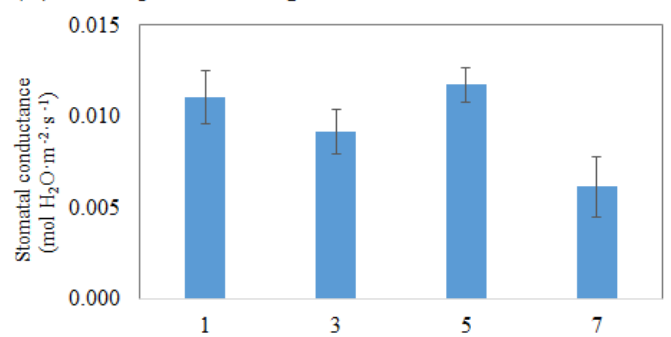

(E) Epipremnum aureum

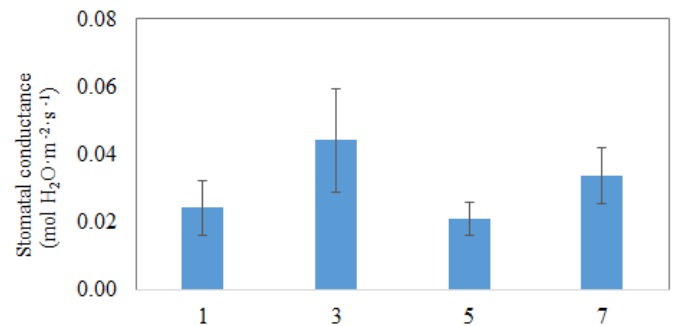

(G) Peperomia clusiifolia

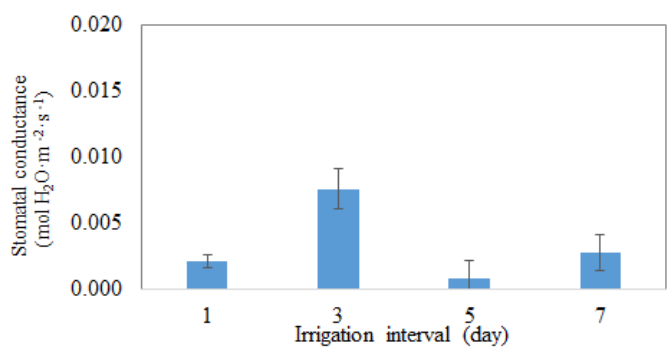

(B) Aglaonema 'Siam_Aurora'

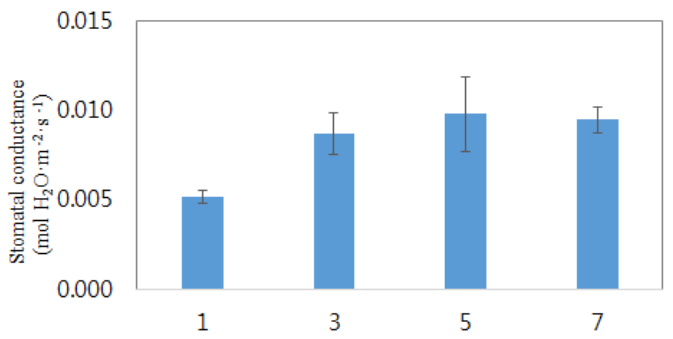

(D) Dieffenbachia 'Marianne'

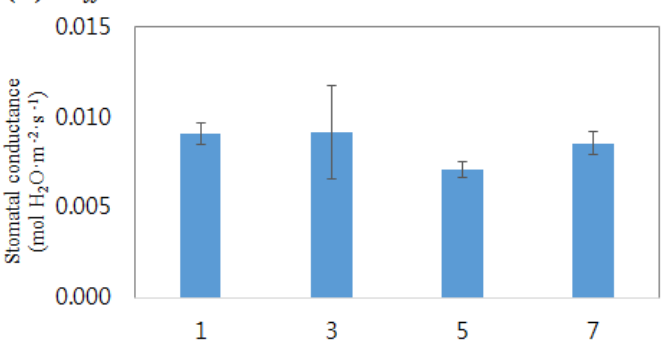

(F) Hedera helix

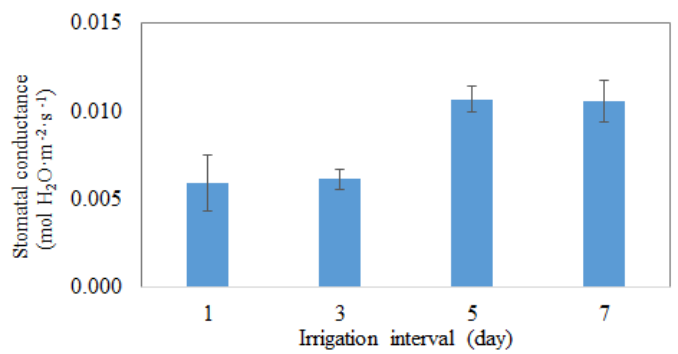

Fig. 2. Effect of irrigation interval cycle on stomatal conductance of indoor plants grown for 3 months bio-wall system. Vertical bars indicate the standard deviation of three separate experiments.

roots was higher in the treatment groups of long irrigation cycles, indicating that the cycle of irrigation affects the development of roots. The length and fresh weight of roots were also high when the cycle of irrigation was 7 days (Figs. 4C and 5C).

The total number of roots of Aglaonema 'Siam-Aurora' rather decreased when it was watered at the interval of 7 days. The development of roots at the irrigation cycles of 1 and 3 days was different. Roots of $5 \mathrm{~cm}$ or shorter were observed more at the interval of 1 day, while roots of $10 \mathrm{~cm}$ or longer were observed more at the interval of 3 days. The fresh weight of roots at the irrigation cycle of 3 days was the highest, indicating that watering once per 3 days is suitable for the development of roots (Fig. 5B). The root development patterns of Aglaonema were also similar to those of Aglaonema 'Siam-Aurora' but differences between treatment groups were not significant. The total number of roots of Dieffenbachia 'Marianne' 
(A) Aglaonema

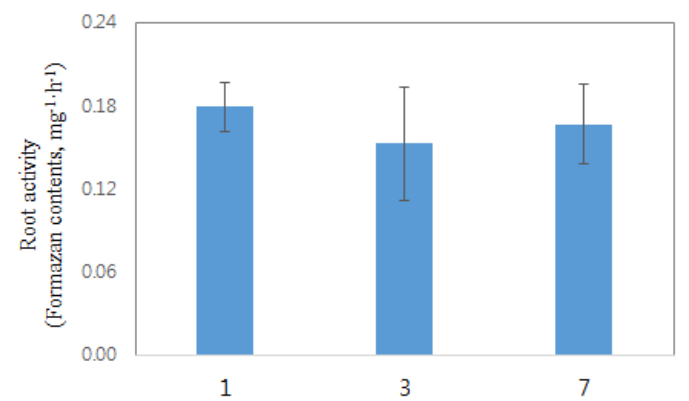

(C) Ardisia pusilla 'Variegata'

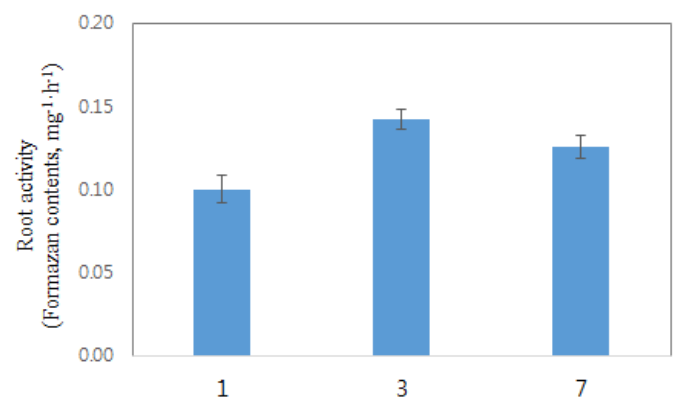

(E) Epipremnum aureum

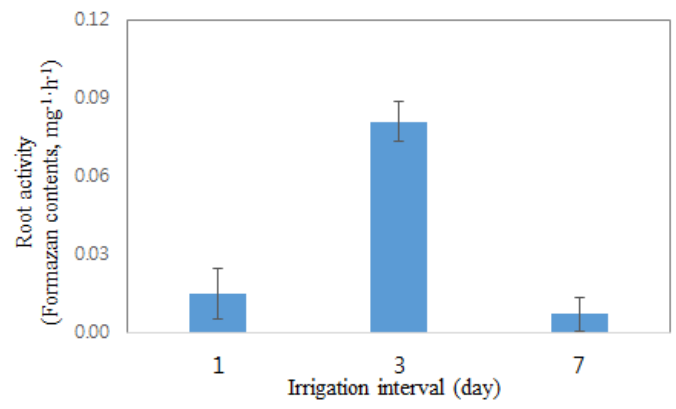

(B) Aglaonema 'Siam_Aurora'

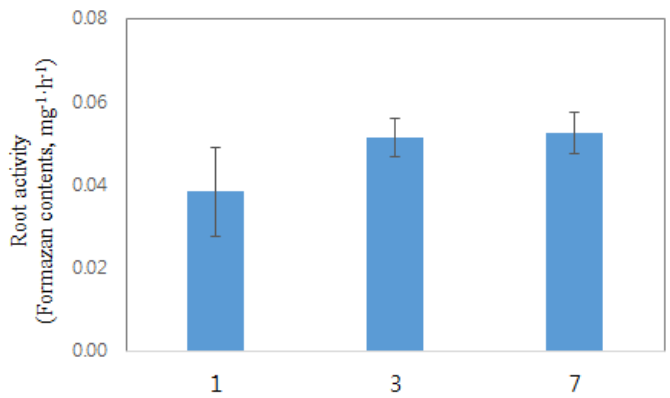

(D) Dieffenbachia 'Marianne'

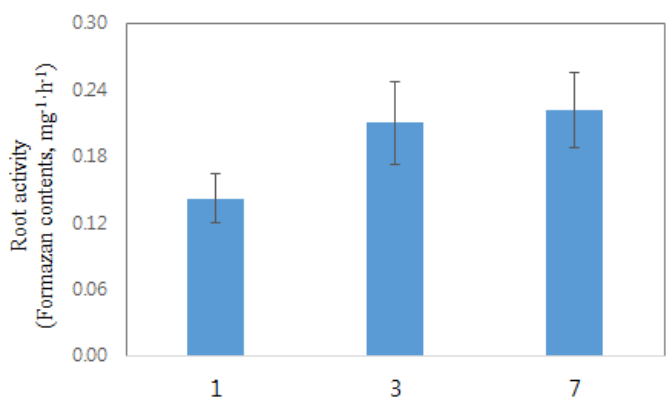

(F) Peperomia clusiifolia

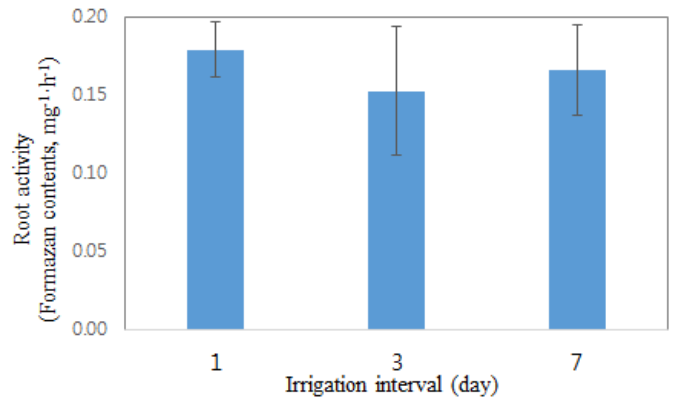

Fig. 3. Effect of irrigation interval cycle on root activity of indoor plants grown for 3 months bio-wall system. Vertical bars indicate the standard deviation of three separate experiments.

at the irrigation cycle of 3 days was about 2 times higher than other treatment groups, and the development of roots at the intervals of 1 and 7 days was relatively lower. No significant difference was observed in the length of roots between the 3 treatment groups. The fresh weight of roots at the intervals of 1,3 and 7 days was 2.0, 3.9 and 1.6 $\mathrm{g}$ respectively and the fresh weight was found to be the highest at the irrigation cycle of 3 days, indicating that watering once per 3 days is suitable for the development of roots (Figs. 4D and 5D).

In the case of Epipremnum aureum, the total number of roots at the irrigation cycles of 3 and 7 days was higher than that at the interval of 1 day, and the length of roots was also longer at the intervals of 3 and 7 days. In addition, compared to the fresh weight of roots at the interval of 1 day (2.5 g), watering once per 3 and 7 days (4.1 and $3.8 \mathrm{~g}$ respectively) was found to be suitable for the development of roots (Fig. 5E).

The development of roots of Hedera helix at different irrigation cycles was measured, short roots tended to be observed more at the irrigation cycles of 3 and 7 days, but there was no significant difference in the total number of roots. In terms of the length of roots, long roots were observed more when it was watered at the interval of 7 days, and the fresh weight of roots also tended to be slightly higher at the interval of 7 days (Fig. 5F).

The growth characteristics of the underground part of the 7 foliage plants, introduced to an indoor vertical bio-wall 
(A) Aglaonema

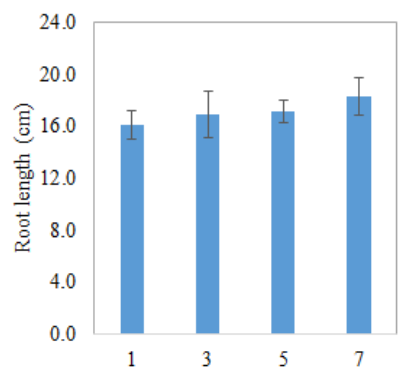

(E) Epipremnum aureum

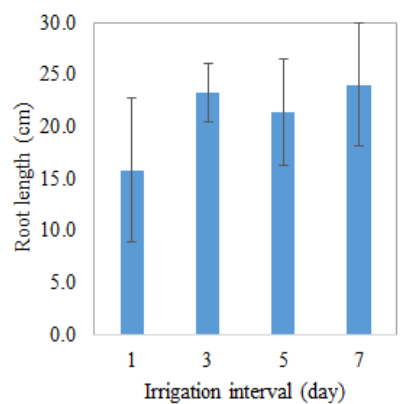

(B) Aglaonema 'Siam_Aurora'

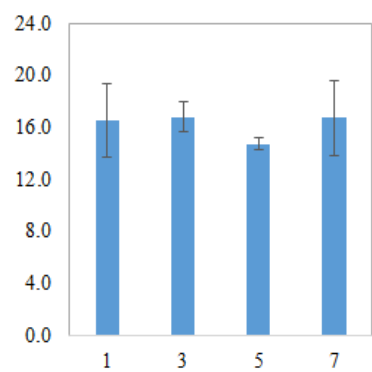

(0)Hedera helix

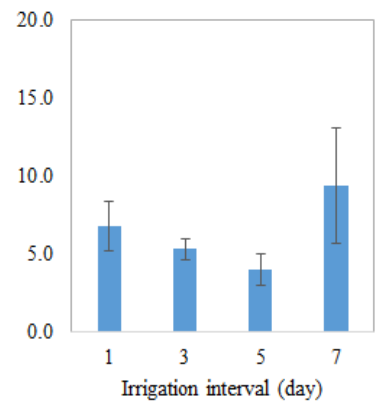

(C) Ardisia pusilla 'Variegata'

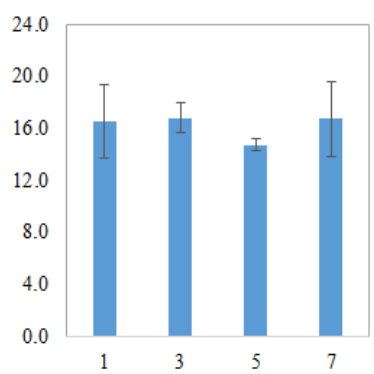

(G) Peperomia clusiifolia

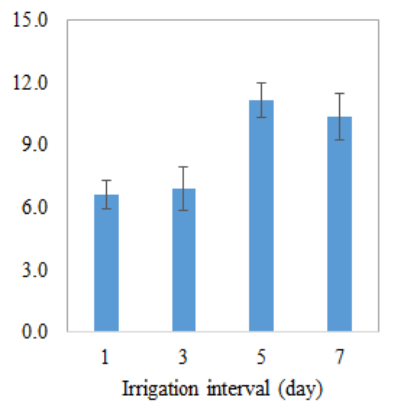

(D) Dieffenbachia 'Marianne'

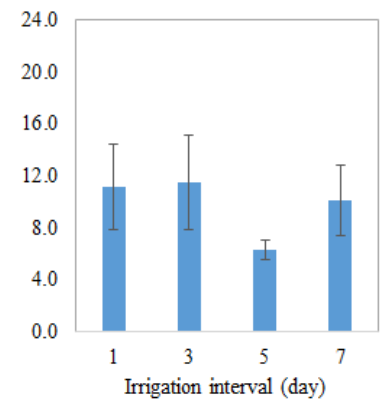

Fig. 4. Effect of irrigation interval cycle on root length of indoor plants grown for 3 months bio-wall system. Vertical bars indicate the standard deviation of three separate experiments.

(A) Aglaonema

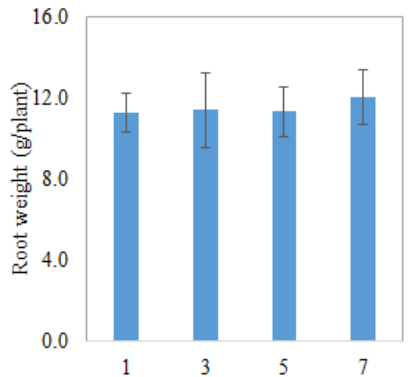

(E) Epipremnum aureum

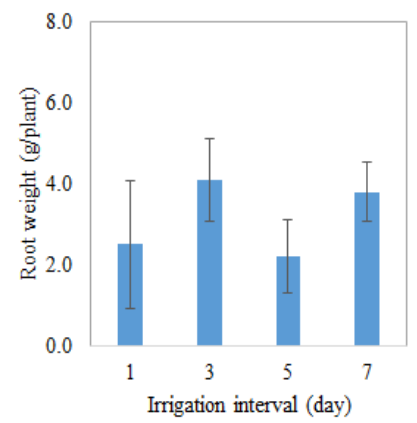

(B) Aglaonema 'Siam_Aurora'

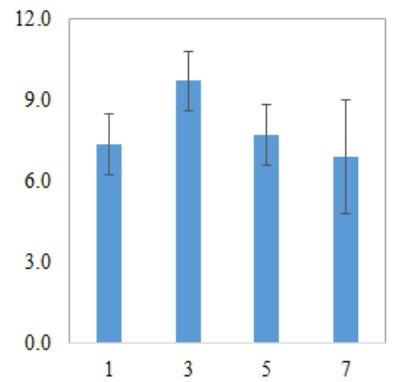

(F) Hedera helix

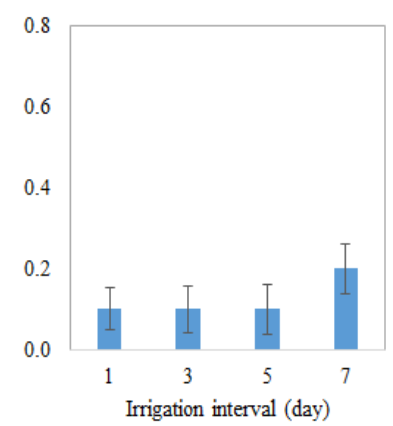

(C) Ardisia pusilla 'Variegata'

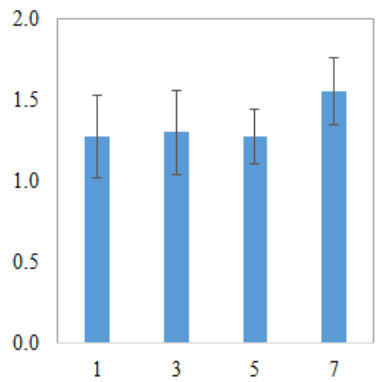

(G) Peperomia clusiifolia

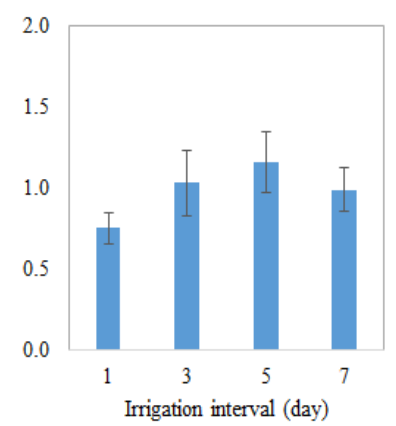

(D) Dieffenbachia 'Marianne'

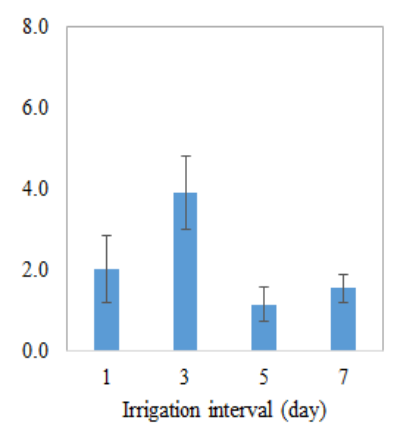

Fig. 5. Effect of irrigation interval cycle on root fresh weight of indoor plants grown for 3 months bio-wall system. Vertical bars indicate the standard deviation of three separate experiments. 
system that used a bottom watering method, at different irrigation cycles were examined, and the overall growth of the underground part of the plants watered at the interval of 3 days was found to be good. Although irrigation cycles need to be managed differently depending on the species of plants, it seems that watering once per 3 and 5 days has a positive impact on changes in the aerial part of plants and the development of their underground part.

\section{Conclusion}

To improve the effects of plants on indoor air purification, it is necessary to place plants on $5-10 \%$ of indoor spaces, and people's interest in and studies on bio-wall, a vertical green wall system, have recently increased in order to increase the density and utilization of plants in indoor spaces. This study was conducted to examine the growth characteristics and the rooting zones of indoor plants, under different irrigation conditions, that were introduced to the bio-wall system including Peperomia clusiifolia, Ardisia pusilla 'Variegata', Aglaonema 'Siam-Aurora', Aglaonem, Dieffenbachia 'Marianne', Epipremnum aureum, and Hedera helix, and to identify a proper irrigation cycle for the sustainable maintenance of bio-wall systems. To maintain a constant indoor growth environment for testing plants, the intensity of light was maintained at 20-50 $\mu \mathrm{mol} \cdot \mathrm{m}^{-2} \cdot \mathrm{s}^{-1} \mathrm{PPFD}$, and the temperature was maintained at $20-25{ }^{\circ} \mathrm{C}$. For fertilization, Hyponex diluted at the ratio of 1:1,000 was supplied to plants once a month. Irrigation was performed at intervals of $1,3,5$ and 7 days for 1 hour at a time. Differences in the growth of the plants were not significant, but the number of leaves of Dieffenbachia 'Marianne' when the cycle of irrigation was the longest (7 days) was greatly reduced. In addition, the content of chlorophyll was relatively low at the interval of 7 days, and in terms of the color of leaves, it showed a decrease in the $\mathrm{L}$ value, an increase in the a value and a decrease in the $b$ value, showing changes in the color of leaves such as a slight decrease in brightness, a decrease in the color of yellow and a slight increase in the color of red. Ardisia pusilla 'Variegata' showed a slightly high photosynthetic activity and stomatal conductance when it was watered at the interval of 1 and 5 days, and Epipremnum aureum showed a relatively high photosynthesis activity and stomatal conductance only at the irrigation cycle of 3 days. The activity of roots was found to be mostly high when it was watered at longer intervals, rather than everyday. Peperomia clusiifolia showed the accelerated development of roots when the cycle of irrigation was long, while the total number of roots of Aglaonema 'Siam-Aurora' was reduced at the irrigation cycle of 7 days. In conclusion, watering plants at the interval of 3 days seems to be suitable for the sustainable management of vertical bio-wall systems.

\section{References}

Choi, S.R. and Y.S. Kim. 2014. The analysis of plant color change according to the changing growing environment of indoor wall plant space: On the basis of wall planting of the Eco-plaza in the new Seoul city hall building. J. Korea Inst. Spat. Des. 9(4):107-115. https://doi.org/ 10.35216/kisd.2014.9.4.107

Darlington, A., J.F. Dat, and M.A. Dixon. 2001. The biofiltration of indoor air: Air flux and temperature influences the removal of toluene, ethyl benzene and xylene. Environ. Sci. Technol. 35(1):240-246. https://doi. org/10.1021/es0010507

Guieysse, B., C. Hort, V. Platel, R. Munoz, M. Ondarts, and S. Revah. 2008. Biological treatment of indoor air for VOC removal: Potential and challenges. Biotechnol. Adv. 26(5):398-410. https://doi.org/10.1016/j.biotechad v.2008.03.005

Han, S.W. and J.S. Lee. 2002. Purification efficiency of $\mathrm{O}_{3}$ and $\mathrm{SO}_{2}$ by some oriental orchids. J. Korean Soc. Hortic. Sci. 43(4):487-491.

Irga, P.J., T.J. Pettit, and F.R. Torpy. 2018. The phytoremediation of indoor air pollution: a review on the technology development from the potted plant through to functional green wall biofilters. Rev. Environ. Sci. Biotechnol. 17:395-415. https://doi.org/10.1007/s11157018-9465-2

Jang, T.K., H.Y. Kim, and K.B. Lim. 2013. Selection of artificial media suitable for the growth of foliage plants for indoor vertical garden. Flower Res. J. 21(1):11-16. 
Kim, K.J., M.J. Kil, J.S. Song, E.H. Yoo, K.C. Son, and S.J. Kays. 2008. Efficiency of volatile formaldehyde removal by indoor plants: Contribution of aerial plant parts versus the root zone. J. Am. Soc. Hortic. Sci. 133(4):521-526. https://doi.org/ 10.21273/JASHS.133.4.521

Mitchell, C.S., J. Zhang, T. Sigsgaard, M. Jantunen, P.J. Lioy, and R. Samson, and M.H. Karol. 2007. Current state of the science: Health effects and indoor environmental quality. Environ. Health Perspect. 115(6):958-964. https://doi.org/ 10.1289/ehp.8987

Park, S.H., Y.B. Lee, G.Y. Bea, and M. Kondo. 1999. Anion evolution in plants and its involved factors. J. Korean Soc. Hortic. Sci. 39(1):115-118.

Pérez-Urrestarazu, L., G. Egea, A. Franco-Salas, and R. Fernández-Caňero. 2014. Irrigation systems evaluation for living walls. J. Irrig. Drain. Eng. 140(4):04013024. https://doi.org/10.1061/(ASCE)IR.1943-4774.0000702

Pettit, T., P.J. Irga, and F.R. Torpy. 2018. Towards practical indoor air phytoremediation: A review. Chemosphere 208:960-974. https://doi.org/10.1016/j.chemosphere.201 8.06 .048

Ro, S.M., J.S. Lee, and Y.S. Kim. 2003. Analysis of the environment and plant growth on wall surface afforestation in Seoul. J. Korean Flower Res. Soc. 11(2):157-166.
Sundell, J. 2004. On the history of indoor air quality and health. Indoor Air 14(Suppl. 7):51-58.

Torpy, F., N. Clements, M. Pollinger, A. Dengel, I. Mulvihill, C. He, and P. Irga. 2017. Testing the single-pass VOC removal efficiency of an active green wall using methyl ethyl ketone (MEK). Air Qual. Atmos. Health 11:163-170. https://doi.org/10.1007/s11869-017-0518-4

Torpy, F.R., M. Zavattaro, and P.J. Irga. 2017. Green wall technology for the phytoremediation of indoor air: A system for the reduction of high $\mathrm{CO}_{2}$ concentrations. Air Qual. Atmos. Health 10:575-585. https://doi.org/10. 1007/s11869-016-0452-x

Wolverton, B.C., A. Johnson, and K. Bounds. 1989. Interior landscape plants for indoor air pollution abatement (NASA report NASA-TM-101766). Retrieved from https://ntrs.nasa.gov/search.jsp?R=19930073077

Wolverton, B.C. and J.D. Wolverton. 1993. Plant and soil microorganisms: Removal of formaldehyde, xylene and ammonia from the indoor environment. J. Mississippi Acad. Sci. 38(2):11-15.

Wu, F., D. Jacobs, C.S. Mitchell, D. Miller, and M.H. Karol. 2007. Improving indoor environmental quality for public health: Impediments and policy recommendations. Environ. Health Perspect. 115(6):953-957. https://doi.org/10.1289 /ehp. 8986 